\title{
WHAT ARE DEMANDING OPERATIONS IN SUBSEA WORK?
}

\author{
JON IVAR HÅVOLD ${ }^{1}$, LILLIAN VEDERHUS ${ }^{1,2} \&$ STEINAR NISTAD \\ ${ }^{1}$ Norwegian University of Science and Technology, Norway \\ ${ }^{2}$ The Arctic University of Norway, Norway
}

\begin{abstract}
In recent years, offshore operations have changed from a focus on anchor handling and rigging to more subsea installation and IMR (inspection, maintenance, repair). Situations where large and heavy modules are placed on the seabed by increasingly specialized and bigger boats creates the potential for major accidents. To uncover the safety challenges of this new development, 14 semi-structured in-depth interviews were conducted covering a broad scope of experience and skills from subsea work (ROV operators, crane operators, captains/first/second mates, oil service and oil company operators). All interviewees claimed that moving the offshore oil operations from surface to subsea leads to more demanding operations and more complex and risky work situations. According to the informants, these developments mean that cooperation and communication are essential since the number of actors increases substantially and the units grow larger. This seems to place increased demands in understanding both culture, language, tools, potential events, possible preventative measures (including training) and handling when critical events occur. Demanding situations occur when customers push on weather limits and costs and there are fewer people at work. Other situations viewed to be demanding are when something is hoisted through splash zones, and the moment when heavy constructions are placed on the seabed template. It has been shown that simulation training can improve safety and be an important preventive safety measure.
\end{abstract}

Keywords: demanding work, maritime operations, subsea work, safety, risk, interview.

\section{INTRODUCTION AND BACKGROUND}

In recent years, the offshore industry has been experiencing a development where activities are directed from installations on the surface to "subsea operations". Technological innovations have resulted in extraction of oil and gas from deeper water, and structures on the seabed where small oil and gas fields are connected to existing installations. Demanding maritime operations have changed from a focus on anchor handling and rig-move operations to an increasing number of subsea installation and IMR (inspection, maintenance, and repair). This development creates new safety challenges and it is very important to develop competence and shed light on the risks this new development brings, so barriers to critical events can be implemented. Interaction seems to be an essential part of the "new" risks because the number of actors has increased and the units have become larger. This makes greater demands in understanding culture, language, tools, possible preventive measures (including training) and how to handle critical events.

The crew's skills, knowledge, experiences and attitudes are important for efficiency, safety and the environment. Knowledge and competence can help develop generic operational models for demanding scenarios, and focus research issues that emphasize safety interventions both in terms of barriers and training. Team training using simulators has been successful in anchor handling [1], and using simulators could help with preventive "safety measures" for subsea as well.

According to International Maritime Organization (IMO), simulator training programmes concerning the new subsea challenges are not being implemented and it is urgent that there is an evidence-based approach and a broad professional and geographical foundation in the 
development of such programmes. How can demanding subsea scenarios be created and simulated so that training can contribute to more resilient players in subsea operations?

The main goal/research question is to uncover and contribute knowledge to a deeper understanding of what is perceived to be demanding during maritime operations in subsea work.

\section{MATERIAL AND METHODS}

The research goal suits a qualitative, methodical approach. According to Thagaard [2] a qualitative approach provides the basis for an understanding of a social phenomenon, based on data from the people and situations being studied. It is characterized by a focus on the process and meaning, analysis of text and proximity to the informants. Qualitative methods such as focus groups and interviews are a good way to investigate little researched subjects, and where demand for flexibility and transparency is needed [2]. This research uses a phenomenological approach, which is based on individuals' experiences [3]. How an individual experiences a situation, and what they feel and think is of importance. The starting point of the phenomenological perspective is that reality is as the informant perceives it. It is all about understanding and lifting out social phenomena from the informant's own perspective, as well as highlighting the informant's description and central meaning.

\subsection{Data collection strategy}

In the project plan, focus groups were suggested for the data collection; however, using focus groups proved difficult because of unforeseen problems caused by the decrease in oil demand and oil prices during 2014. Increased competition between some of the companies meant that the members of the focus groups did not feel comfortable expressing their views in front of other group members: some members considered themselves to be more experienced than others, and preferred to keep their knowledge to themselves. Focus groups work best when the participants are comfortable with other group members [4].

In view of this, the project team decided to conduct an interview survey using in-depth interviews instead, which according to Ulrich and Eppinger [4] is a good alternative to focus groups.

\subsection{Research interview}

The interview process includes both planning, execution and finishing work. Dalen [5] describes the choice of informants as a particularly important topic in qualitative research. The number of informants cannot be too large since data collection and data processing is a time-consuming process; however, the interview material must provide sufficient material for analysis. The number of informants depends on the purpose of the research [6]. In our study it was important to bring informants from several parts of the "value chain" covering subsea activities. Fourteen interviews were conducted in the period from September 2014 to April 2015. Participants were well qualified to participate in the research, as all had years of experience in offshore and subsea operations from shipping companies, oil companies, petroleum service companies and industrial and government agencies (see Table 1).

\subsection{Interview guide}

In-depth, semi-structured interviews enabled us to capture different people's perspectives, general offshore experience and expertise related to subsea operations. This is in line with Thagaard [2] who claims that the interview is particularly well suited for providing 
Table 1: Data collection (interviews).

\begin{tabular}{|c|l|l|}
\hline $\begin{array}{c}\text { Date of } \\
\text { collection }\end{array}$ & Data source & Type of organization \\
\hline $9 / 2014$ & Senior engineer & Ship building \\
\hline $9 / 2014$ & Subsea responsible & Public supervisory authority 1 \\
\hline $10 / 2014$ & $\begin{array}{l}\text { Group interview - education and } \\
\text { training manager, HMSQ leader }\end{array}$ & Ship-owner 1 \\
\hline $10 / 2014$ & Interview - senior employee & Oil service company 1 \\
\hline $2 / 2015$ & Group interview & $\begin{array}{l}\text { Oil company, oil service } \\
\text { company } 2\end{array}$ \\
\hline $2 / 2015$ & Interview & Oil service company 3 \\
\hline $2 / 2015$ & Chartering manager & Ship-owner 1 \\
\hline $2 / 2015$ & HMSQ leader & Ship-owner 2 \\
\hline $3 / 2015$ & Captain & Ship-owner 3 \\
\hline $3 / 2015$ & Captain & Ship-owner 4 \\
\hline $4 / 2015$ & Crane instructor & Education/training \\
\hline $4 / 2015$ & ROV training manager & Oil service company 4 \\
\hline $4 / 2015$ & ROV operator & Oil service company 4 \\
\hline $4 / 2015$ & Manager HMSQ department & Public supervisory authority 2 \\
\hline
\end{tabular}

information on informants' experience and views. The interview guide (Appendix 1) was structured to cover areas that provided the basis for addressing the research problem. We aimed to meet the informants openly, with the intent of allowing their descriptions to be a starting point for further analytical work, theory anchoring and discussion. In qualitative interviews, it is important to safeguard the integrity of the interviewees, both at the interview and when the results are presented and interpreted, so all respondents were anonymized and sensitive information was treated with caution.

\subsection{Semi structured interview}

In this research, it is important to emphasize the informants' own experiences, opinions and perspectives on where the risks exist in subsea activities. To obtain this knowledge, the project team felt that in-depth, semi-structured interviews were equally suited for acquiring data as focus group interviews. In choosing this type of interview, we wanted an equal relationship between interviewer and interviewee, creating trust and confidence in us as scientists. The informant should feel that the researcher is interested in what they say through both nonverbal and verbal communication.

\subsection{Collection of data materials}

Interviews were conducted between 23rd September 2014 and 17th April 2015 and lasted between 35 minutes and one hour and 25 minutes. Some of the interviews were conducted at the University while some took place at the workplace of the interviewee. The three authors of this paper shared the interviews between them, however in a few interviews there were two interviewers present. In these cases, there was a main interviewer. 


\subsection{Transcription of computer material}

To transcribe means to change from one form to another, to transform. In this context, there is the transformation from spoken language to written language. The interviews are conducted and transcribed in Norwegian, but the quotes used in this paper have been translated into English by the authors. The interviews are semi-structured so that they are better suited for further analysis; it is easier to have an overview and the structure of the interview is the start of the analysis [3]. Since we are using the phenomenological approach, we chose to transcribe word for word to keep the transcripts as true to the interviewees' voices as possible. This helps increase transcription reliability. The interviews were transcribed with laughter, uncertainty, breaks, repetitions etc. The material totalled more than 150 pages of transcribed material set with 12 point Times Roman and 1.5 line spacing.

\subsection{Quality of research}

Fejes and Thornberg [7] use the term quality to discuss qualitative research, whereas Guba [8] and Bryman [9] use credibility as a concept to denote thorough, systematic and well-executed qualitative research. According to several authors [7], [9], [10], there is no clear way of evaluating the quality of qualitative investigations. However, Bryman [9] and Guba [8] have promoted four much used criteria on how qualitative research should be evaluated.

These criteria are:

1. Credibility;

2. Transferability;

3. Dependability; and

4. Confirmability.

The four criteria are equivalent to the internal and external validity, reliability, and objectivity in quantitative research.

Credibility refers to the procedures for establishing confidence in the "truth" of the findings. In order to establish sufficient credibility in this study 14 interviews were conducted with nearly 20 different individuals working on the theme under investigation. Moreover, those who participated in the interviews have worked on safety issues in the maritime oil and gas industry for several years. We believe that this covers an adequate part of Guba's [8] requirements "long-term commitment to an area" and "persistent observation" as important for the credibility of the results.

Transferability refers to the extent to which qualitative results can be transferred to other contexts [8]. The breadth and depth of data collection is important for some degree of transferability between two contexts depending on their similarities and the thickness of the description. Since the findings of this study concern subsea operations that took place mainly in Norwegian waters the results will be less valid and reliable for a different context. However, the purpose of this study has been to portray a thick description that can help with making hypotheses for future studies in similar contexts.

Dependability refers to the stability of the results challenged by weaknesses in the methods or in the researcher as an instrument [8]. This study has a relatively high number of in-depth interviews undertaken by three different interviewers. All interviews were performed in the same way using the same interview guide. When it comes to the reliability of the researchers as an instrument, it can be said that in this study the three researchers worked on a familiar field, even though the subsea area is relatively new. 
Confirmability refers to the degree of confirmability of the study. To ensure a high degree of confirmability, the researchers were critical of their own interpretations, models, theories and references when explaining the findings. We cannot argue that the results of this study are without distortions. The main purpose of the project has been to present and interpret information from people who have worked on subsea operations.

\section{FINDINGS AND DISCUSSION}

In this chapter, results from the interviews are clustered under six headings based on what the interviewees perceive as demanding. One has to be aware that quotes under one heading might overlap with other headings and that all are in one way or another interrelated. All quotes in this chapter are derived from the interviews.

\subsection{Communication, language and cultural differences}

Effective safety communication is the cornerstone of a healthy organizational safety culture. Workplace language barriers create time cost, cause frustration and even endanger lives. What is known from cultural research is that both national culture, organizational culture and safety culture is important and challenging in seafaring in general and in maritime operations such as anchor handling and subsea operations [11], [12]. Most of the interviewees found communication, language and cultural differences challenging with comments such as "Communication can be a big problem"; "Demanding communication, many people and many nationalities involved". Below are some quotes highlighting the importance of communication, language and culture.

Communication is demanding; there can be 15 people on the same link, where some like to keep discussions running and chatting more than others. With eight to nine nationalities on board there are many languages, Filipinos on decks, Scots and English as riggers, one to two from India, some East Europeans, Italians, Americans and Brazilians. We often have to ask people to be brief, and the amount of speech must be controlled when time is scarce. Cultural differences are significant. (First Officer)

Communication and coordination between several groups and the bridge personnel who keep the boat in place might be challenging. (Captain)

It's also important to train in cultural understanding and how to manage stress. (First Officer)

Language problems are more common in Asia and South America and often between ROV and the bridge. Communication between cultures - may be difficult because of different attitudes towards religion and gender. (ROV Pilot)

In subsea, there is mutual dependency. Everyone has to deliver all the time. In traditional anchor handling, the bridge can do a lot alone. The fact that there are many people involved makes communication extra important, with feedback and verification. (Captain)

While language barriers often lead to miscommunication, a culture gap can also underlie miscommunication, work frustration and higher risk. It's important to understand where your people come from-both literally and figuratively. For example, to anticipate how an employee will respond to workplace expectations, and to find out what workplace safety expectations he or she is familiar with. This type of knowledge will improve your other management skills, too. (Captain) 


\subsection{Heavy lifting, operations, cooperation and teamwork}

Correct lifting can move large objects efficiently; however, incorrect lifting during operations can lead to disastrous accidents, causing injuries, loss of work time and property. People, cooperation and teamwork, machinery, loads, methods and the work environment are all important factors for correct lifting. Below are some comments from the interviewees concerning heavy lifting, operations and teamwork.

Operations that are high-risk: lifting, pipe laying, interventions (riserless intervention), ROV services. (Engineer)

Cooperation between ROV, crane, bridge and deck, as well as cooperation between boats, such as lifting from/to barges, between boats and barges and intermediaries is considered risky. (Engineer)

Too little collaboration between equipment vendors and those who use the equipment. Equipment vendors are not included in the cooperation loop and therefore equipment is often used and interpreted incorrectly. (Engineer)

Both heavy lifting and light lifting can be dangerous--but the teams train more in heavy lifting. (Engineer)

The risk is greatest when the load goes through the "splash zone" and when they are placed on the template. (Engineer)

\subsection{Knowledge, competence and training}

Companies are responsible for providing workers with a safe and healthy work environment and for ensuring that they are trained in the skills and knowledge necessary for working in a safe and reliable way [1]. Several of the interviewees found lack of knowledge, competence and training challenging in a subsea context.

Training in handling the boat manually is needed to increase safety. You can be "off" DP (Dynamic Positioning) for 10 hours - many have driven a boat before, but not "this boat". No idea how each individual boat works manually. One can in principle take over as First Officer at 23 years old, having to run without DP not knowing the boat. Training in cultural understanding and stress management are also important. (First Officer)

Training in subsea jobs is pretty much on the job training. I do not know of any special training on subsea operations. I am afraid that the training at subsea will be very vessel specific. (Captain)

The procedures are probably evaluated, but one cannot test them in practice with movement. By using simulation training, one can be much safer. (Engineer)

By using simulations, one can check whether the boat is usable for the purpose. It has to simulate different types of weather and different wave heights. (Engineer)

Need for stability simulations. Many safety events in recent years are to do with stability on rigs. (Captain)

Very different quality of simulators. There should be regulations determining the quality of simulator facilities; what exists is outdated. (Captain) 
By using a simulator, it is possible to train on difficult scenarios something impossible to do in on the job training. (Captain)

Simulator courses should be used to train in procedures, but also to provide attitude changes to improve team performance. Some work well together but with others it is just arguing and quarrelling (name omitted from example). It is important to watch the interaction so that one can give that little extra. (First Officer)

Another challenge is the "stop criteria" and cross pressure. To train on practicing the abandonment criteria is quite essential, but it must be followed by discretion and holistic understanding. (First Officer)

\subsection{Complexity}

Complexity is subjective; it is not in the system itself but in the minds of observers or users of the system. What is complex to one person or at one point in time may not be to another. The problem is that new technology allows almost unlimited complexity in the systems we are building. This complexity is creating new causes of accidents and changing the relative importance of traditional causes. Training (see Section 3.3) is important in connection to complex systems, but to train for the unforeseen is difficult and demanding. Complexity in demanding situations is not linear, therefore they are less transparent and more difficult [13].

Great complexity - much coordination between several groups and the staff on the bridge whose job is to hold the boat in place. (Captain)

Many parties cooperates in subsea operations. Time constraints, many involved and large costs in subsea operations make it all complex. (Crane Operator)

The systems are becoming very complex and there is a major lack of system understanding. (First Officer)

Competence requirements and knowledge of work duties are much greater for offshore subsea than those of onshore construction sites. (Captain)

Subsea is demanding because you do not see things with your own eyes, but have to use the camera to get an overview. (Captain)

\subsection{Rules and procedures}

There is a saying, "Proper prior planning prevents poor performance". Rules and procedures are designed to ensure that work activities can be performed safely. Some measures are required by legislation, and compliance is essential. Additional measures mandated by companies as the minimum standard are implemented, and in some cases, further measures may be added based on specific site requirements. The interview indicates that in this relatively new area, things can be done to improve safety.

Poor planning, rare personal things or procedure violations. (Captain)

The regulations in training are complicated. We have to spend a lot of time explaining and interpreting them. (Captain)

The scope of work (the work plan), which is often voluminous with a many details; everyone must look through a variety of details to find and select what is of relevance for their work. It is demanding with overly complex systems. (First Officer) 
The Petroleum Safety Authority is not sufficiently interested in revising the regulations together with the oil and gas industry, so they can correspond with practice. The frustrations are great since the regulations used really do not cover offshore. They have been introduced there because some paragraphs fit and because of that, they let them all apply. (ROV Operator)

The regulations are not designed for the activities on the boat. Petroleum Safety Authority regulations are designed for a rig. (Captain)

\subsection{Pressure and stress}

Work related stress is the process that arises when the demands of work exceed a person's capacity to cope. Job related psychological stress is often attributable to high work demands, pressure, and limited scope for decision-making. Work pressure indicates how people perceive their work. Several authors include the work situation as one of the main factors influencing behaviour [14]. Many of the interviewees mentioned pressure and stress as two of the factors that make subsea operations demanding.

Technology and tempo increase - the jobs become more demanding. (Crane Operator)

It is important for the team to train in cultural understanding and stress handling. (First Officer)

Pressure to reach a weather "window" and pressure to complete the project. This is the highest safety risk in projects. (Captain)

Potential cross-pressure when weather, wind, and streams are in borderland. (Captain)

Pressure!! Customers can try to push us on weather, on costs, to have fewer people at work. Pressure to work whatever the consequences might be. (ROV Pilot)

Many parties cooperates in a subsea operation. Time constraints, numbers of people involved and high costs makes it all complex. (Crane Operator/Manager)

For ROV, there are those movements from bad weather in the boat that are demanding. Under water, it is not a problem for ROV. (ROV Pilot)

People relax between jobs, lower their shoulders and are not observant. ROV slips out of the latch and the cargo falls. (Captain)

4 CONCLUSION, LIMITATIONS AND PRACTICAL IMPLICATION

This paper's main goal is to uncover and contribute knowledge to a deeper understanding of what is perceived as demanding during maritime operations in subsea work.

The methodology used in this research is evaluated as credible, dependable and confirmable. The quotations in chapter three show that experienced informants describe many operations as demanding in subsea operations; however, since we have more than 150 pages of transcribed material, further analysis of this data might give us an even deeper insight.

A limitation of this research is also that it is based only on interviews with Norwegian informants; further research with a broader sample might give different results.

The role of practitioners in demanding subsea operations is important. They are at the sharp end where knowledge, skills and attitude are important antecedents to behavior [1]. 
The interviewees suggest important practical implications through their comments reported in Section 3.3, Knowledge, competence and training. Many of the suggestions include education and training by using simulators. The training could cover both technical matters such as stability and heavy loads, and human factors such as communication, cooperation, culture, teams, language, pressure and stress, as well as a combination of technical and human factors in situations where there are different weather conditions, loss of DP or engine malfunction.

One of the captain's interviewed described the future as bringing "More and more modules, bigger and bigger modules. More and more specialized, bigger and bigger boats".

\section{ACKNOWLEDGEMENTS}

We would like to thank all informants and the companies who enrolled in the interviews. The Regional Research Funds Mid Norway funds this research.

\section{APPENDIX 1: INTERVIEW GUIDE}

Research questions Interview questions

1 What formal and real

Could you tell me a little about your background?

competence does the interviewee have?

a) Job position

b) Age

c) Training

d) Total work experience

e) Experience from SUBSEA - Type of boat/operation

Describe your job?

What do you think you are capable of in terms of work to be done?

What would a colleague, who knows you well, say were your strongest sides?

2 What are demanding situations associated with SUBSEA?
What situations/conditions do you perceive as difficult/ difficult during a SUBSEA operation?

Have you experienced any injuries or accidents onboard?

-If yes, can you explain?

Do you have experience of demanding situations?

-If yes, can you explain?

Do you know others who have experienced challenging situations?

-If yes, can you explain?

Are any of the following conditions experienced as

demanding during an operation:

- Cooperation

- Communication

- Stress

- Weather and sea conditions

- Equipment

- The job itself

Are there any specific risks associated with SUBSEA?

When you report deviations, what are these? 
3 What training is given to those who perform SUBSEA operations?

4 Is there a danger of cross-pressure between the desire to get the job done and safety?

5 What new SUBSEA operations can you expect in the future?
What training/courses is given to those who perform SUBSEA operations, as far as you know?

Is there work where training on the performance is carried out before the operation itself?

Briefing/debriefing - is it done? How? What effect does it have?

What training have you participated in?

Is the training available today good enough? Sufficient?

If you were in charge of this training, how would you like to implement it?

What status should simulator training have?

Often many people are involved in a SUBSEA operation. Can you imagine new ways of training in cooperation?

What is most important, in theory and practice: to get the job done or to take care of safety?

- Does one have to make such choices often?

- In what situations?

When does a job become so dangerous that it should be stopped?

Many people expect a number of new types of SUBSEA operations to be implemented in the future.

Do you see any such operations? If so, which?

Do they bring new challenges?

What should have been included/asked for in addition to what is mentioned above?

\section{REFERENCES}

[1] Håvold, J.I., Nistad, S., Skiri, A. \& Ødegård, A., The human factor and simulator training for offshore anchor handling operators. Safety Science, 75, pp. 236-145, 2015.

[2] Thagaard, T., Systematikk og innlevelse: en innføring i kvalitativ metode, Bergen Fagbokforlaget, 2009.

[3] Kvale, S. \& Brinkmann, S., InterViews: Learning the Craft of Qualitative Research Interviewing, SAGE Publications: Los Angeles, 2009.

[4] Ulrich, K.T. \& Eppinger, S.D., Product Design and Development, 6th ed., McGrawHill: New York, 2016.

[5] Dalen, M., Intervju som forskningsmetode: en kvalitativ tilncerming, Universitetsforlaget, 2004.

[6] Postholm, M.B., Kvalitativ metode. En innføring med fokus på fenomenologi, etnografi og kasusstudier, Universitetsforlaget, 2010.

[7] Fejes, A. \& Thornberg, R., Handbok i kvalitativ anays, Liber: Stockholm, 2009.

[8] Guba, E., Criteria for assessing the trustworthiness of naturalistic inquiries. Educational Technology Research and Development, 29(2), pp. 75-91, 1981.

[9] Bryman, A., Social Research Methods, Oxford University Press, 2012.

[10] Miles, M.B., Huberman, A.M. \& Saldaña, J., Qualitative Data Analysis: A Methods Sourcebook, 3rd ed., SAGE Publications: Thousand Oaks, CA, 2014.

[11] Ek, Å., Runefors, M. \& Borell, J., Relationships between safety culture aspects: A work process to enable interpretation. Marine Policy, 44, pp. 179-186, 2014.

[12] Håvold, J.I., National cultures and safety orientation: A study of seafarers working for Norwegian shipping companies. Work \& Stress, 21(2), pp. 173-195, 2007. 
[13] Vederhus, L., Ødegård, A., Nistad, S. \& Håvold, J., Perceptions of demanding work in maritime operations. Safety Science, in press.

[14] Håvold, J.I., Stress on the bridge of offshore vessels: Examples from the North Sea. Safety Science, 71, pp. 160-166, 2015. 